\title{
The treatment of inflammatory polyneuropathy by plasma exchange
}

\author{
MLP GROSS, NJ LEGG, MC LOCKWOOD, C PALLIS
}

From the Department of Medicine (Neurology and Nephrology), The Hammersmith Hospital and Royal Postgraduate Medical School, London, UK

SUMMARY Observations are reported on six patients with inflammatory polyneuropathy who were treated by plasma exchange. In four cases the polyneuropathy was acute and in two it was chronic or relapsing. Two acute cases and one chronic relapsing case had plasma exchange during a rapidly progressive phase of the disease, and showed a prompt and substantial recovery of function. The other three patients were exchanged when disease activity had reached a plateau. Only minor degrees of improvement were seen in two of these cases. One patient showed an initial mild deterioration before subsequent recovery. There were no significant side effects. These findings are discussed in relation to the pathogenesis and clinical management of inflammatory polyneuropathy.

Acute inflammatory polyneuropathy, or the Guillain-Barré syndrome, is usually a monophasic illness, but cases with an initially similar presentation may pursue a chronic relapsing or a chronic progressive course. Cell-mediated immunity plays an important part in the pathogenesis of the disorder. ${ }^{12}$ Considerable evidence exists, however, both in the clinical context and in the animal model of experimental allergic neuritis, that humoral factors may also be involved. ${ }^{3}$ Complement-fixing antibodies against nerve tissue have been found in $50 \%$ of patients with acute inflammatory polyneuropathy, ${ }^{4}$ and cell-free serum from such patients (and from animals with experimental allergic neuritis) can demyelinate nerve tissue in culture. $^{5}$ IgG and IgM have been demonstrated by immunofluorescence on the surface of nerves in animals with experimental allergic neuritis ${ }^{6}$ and in patients with acute inflammatory polyneuropathy. ${ }^{78}$ This IgG appears to be specific.9 In one study these antibodies were best demonstrated during progression and early recovery of the disease: they were thought to correlate with disease activity. ${ }^{10}$ Circulating immune complexes ${ }^{11}{ }^{12}$ and immune complex deposition in the kidneys were seen in six consecu-

Address for reprint requests: Dr MLP Gross, Department of Neurological Science, Royal Free Hospital, Pond Street, London NW3 2QG, UK.

Received 9 June 1981 and in revised form 13 March 1982 Accepted 22 March 1982 tive patients with acute inflammatory polyneuropathy. ${ }^{13}$ More recently, serum from animals with experimental allergic neuritis ${ }^{14}$ and from patients with acute inflammatory polyneuropathy ${ }^{15}$ has been shown to induce demyelination when injected subperineurally into rat sciatic nerve.

The treatment of acute inflammatory polyneuropathy is largely supportive. Steroids have often been given, but their effect is doubtful. A recent controlled trial ${ }^{16}$ showed no benefit from prednisone, indeed recovery was significantly less in the treated group. There is also evidence to suggest that steroids may predispose to relapse. ${ }^{17}$ Other agents tried (with mixed results) have included methylprednisolone, ${ }^{18}$ azathioprine, ${ }^{19}$ cyclophosphamide ${ }^{20}$ and 6-mercaptopurine. ${ }^{21}$ Acute inflammatory polyneuropathy may, however, occur in patients already receiving immunosuppressive therapy for renal transplantation ${ }^{22}$ or Hodgkin's disease. ${ }^{23} \mathrm{We}$ first reported the rapid recovery of a single patient with acute inflammatory polyneuropathy following plasma exchange. ${ }^{24}$ Further single cases (or small groups of patients) have since been reported, ${ }^{25-30}$ many of whom responded favourably. In this communication we describe our experience with six further patients. Four had acute inflammatory polyneuropathy and two had chronic relapsing inflammatory polyneuropathy.

\section{Methods}

Plasma exchange Having given informed consent, the 
patients underwent plasma exchange using a Haemonetics model 30 cell separator (Haemonetics Corporation, Boston, USA). Three of the patients had Scribner arteriovenous shunts which enabled three or four litre exchanges to be carried out in less than two hours. The other three patients had venovenous exchanges, using antecubital veins. Total plasma volume exchanges $(55 \mathrm{ml} / \mathrm{kg}$ body weight) were carried out, in which plasma protein fraction was used as a substitute. Appropriate concentrations of potassium and calcium were added to the plasma protein fraction. The volumes of plasma exchanged ranged from 12-28 litres, and the exchanges were spaced out over periods ranging from 4 to 10 days.

Neurological assessment Each patient was clinically assessed on the day of admission and daily thereafter. Muscle strength was graded according to the standard 0-5 MRC scale. Vital capacity and tidal volume were estimated frequently, where indicated. Sensory testing (pin-prick, light touch, vibration sense and position sense) was repeatedly carried out, and the state of the reflexes was recorded regularly. In some instances motor activities such as walking were timed.

Laboratory investigations The following data were obtained on all patients: full blood count, ESR, clotting screen, fasting blood glucose, VDRL, TPHA, C3, C4, immune complexes, ANF, DNA binding, serum proteins, IgG, IgM, IgA, rheumatoid factor, urea and electrolytes, liver function tests, HBsAg, folic acid, B12, and viral antibodies. CSF examination included cell count, protein, glucose, Gram stain, culture, AFB, IgG, VDRL, and viral antibodies. Chest radiographs, ECGs and nerve conduction studies were also performed.

\section{PATIENTS}

Case 1 (HH No 488180) Seven days after a sore throat a 22-year-old woman complained of progressive weakness of the limbs. Examination confirmed the weakness and revealed generalised areflexia and impaired postural sense in both fingers and toes. The CSF contained $1.3 \mathrm{~g} / 1$ of protein but no cells. Motor conduction velocities were 62 $\mathrm{m} / \mathrm{s}$ in the left median, $43 \mathrm{~m} / \mathrm{s}$ in the left ulnar and $30 \mathrm{~m} / \mathrm{s}$ in the left common peroneal nerve. Median and ulnar terminal latencies were prolonged to about $10 \mathrm{~m} / \mathrm{s}$. Sensory nerve action potentials were lost. During her first week in hospital her weakness progressed. She was unable to raise her arms, to lift either heel off the bed against gravity or to flex her neck against resistance. A severe facial diplegia developed, and vital capacity dropped by $75 \%$. At this stage (11 days after the onset of her neurological illness and at a time when her deficit was progressing) she received 3 litre plasma exchanges with plasma protein fraction on four successive days. She improved rapidly after the second exchange, and was able to sit and stand unaided, lift her arms above her head and smile almost normally. After the fourth exchange she could walk unaided and her vital capacity had returned to normal. The sensory deficit responded more slowly, over a period of two weeks. Finally her reflexes returned. Nerve conduction velocities only reverted to normal after six months. All other investigations were normal.
Case 2 (HH No 491934) A 55-year-old man had a diarrhoeal illness followed seven days later by rapidly progressive weakness in all four limbs. The CSF showed no cells and $1.44 \mathrm{~g} / \mathrm{l}$ of protein. All other investigations were normal. The patient rapidly became tetraplegic and his condition then remained static for the next seven days. Thereafter, respiratory function decreased marginally and he developed a severe facial diplegia. At this stage he already had marked muscle wasting. No motor response could be elicited by stimulating the right median or ulnar nerves, but sensory and mixed nerve action potentials were present with normal latencies and ascending conduction velocities. Seventeen days after the onset of weakness he underwent seven 4 litre plasma exchanges with plasma protein fraction. After the sixth exchange there was an improvement in the strength of his neck muscles, but not in the power of any other muscle group. Further deterioration, however, did not occur. He never required respiratory assistance. Improvement has been very slow and incomplete, over a period of two years.

Case 3 (HH No 500170) A 48-year-old man had an influenza-like illness followed after three weeks by a feeling of pins and needles in the left arm and weakness in both legs which prevented him from running upstairs. Over the next 11 days he suffered progressive deterioration so that he could not lift his legs off the bed. On admission he was unable to sit up from the supine position, the triceps muscles were weak bilaterally, and there was global weakness of the legs. He was areflexic, and vibration sense was impaired below the iliac crests. No further deterioration occurred for seven days, but slight muscle wasting was apparent at this stage. The CSF protein was $5 \cdot 1 \mathrm{~g} / \mathrm{l}$ with one white cell per cubic millimetre. Motor conduction velocity in the right lateral popliteal nerve was $34 \mathrm{~m} / \mathrm{s}$ and the right sural nerve action potential was absent. All other investigations were normal. Nineteen days after the onset of the weakness he underwent-on three occasions- -4 litre plasma exchanges with plasma protein fraction. Shortly after the first exchange he felt weaker. Examination revealed increased weakness in the muscles of the forearms and hands. Over the next six days both upper and lower limbs became globally weaker and weakness increased in his abdominal muscles too. His condition then remained static for a week, after which he gradually improved.

Case 4 (RFH No BD 2282) A 42-year-old woman with polycystic kidney disease underwent nephrectomy in 1967. In February 1980 a huge, infected, remaining kidney was removed. She was left with a large open draining abdominal wound. She became septicaemic, and required intensive antibiotic therapy, as well as haemodialysis. Ten days following surgery she developed an acute areflexic paralysis involving all limbs and the respiratory muscles. There were no abnormalities referable to the cranial nerves. She deteriorated over 72 hours, becoming tetraplegic and unable to lift her head from the bed; her vital capacity fell to 0.3 litres with a $\mathrm{pO}_{2}$ of $8.6 \mathrm{kp}$ on $35 \%$ oxygen. The CSF contained $1.2 \mathrm{~g} / \mathrm{l}$ of protein, and no cells. It was not possible, at this stage, to perform nerve conduction studies. In anticipation of ventilatory failure she received plasma exchange concurrently with her haemodialysis; ${ }^{31} 4$ litre 
exchanges with plasma protein fraction ( 3 litres) and fresh frozen plasma ( 1 litre) were carried out on five occasions. After the second exchange there was a prompt and substantial response, with marked improvement in ventilatory function, limb strength and postural sense. After the fifth exchange both biceps reflexes returned. Seven days following plasma exchange she had normal power, but there was still residual impairment of tactile sense. At this stage, motor conduction velocities were normal but $F$ waves were absent. All other investigations were normal. Two weeks later, when fully recovered from her neuropathy, she died of overwhelming septicaemia. Limited necropsy examination of her right ulnar nerve showed no. evidence of demyelination or cellular infiltration.

Case 5 (HH No 373673) A 31-year-old foreman builder had a 13 year history of chronic relapsing inflammatory polyneuropathy. This was associated with mild relapsing glomerulonephritis, with C3 and IgG deposition in the glomeruli shown by immunofluorescence of renal biopsy material. During his paretic attacks the CSF protein was always elevated (up to $2.6 \mathrm{~g} / \mathrm{l}$ ). Initially each relapse was treated with steroids: clinical recovery began after some two weeks and was complete after about two months. However both prednisolone (60 mg/day) and ACTH (80 units/day) proved ineffective for a relapse in 1977, and were therefore discontinued. He was given azathioprine (100 mg/day) with a slow but satisfactory response, and the drug was stopped in August 1978. In December 1978 there was a slow, progressive clinical relapse. He developed tingling in the fingers and toes with loss of tactile and pain sense over the hands and feet. He became areflexic and vibration sense was lost below the level of the iliac crests. Position sense was grossly impaired, both proximally and distally. Power was diminished in all limbs and his gait was unsteady, preventing him from working. Conduction velocity in the right median nerve was $44 \mathrm{~m} / \mathrm{s}$ and the terminal latency was $9 \mathrm{~ms}$. No drugs were given, but between February 19 and February 221979 he underwent 4 litre plasma exchanges with plasma protein fraction on four occasions. After the second exchange there was some improvement of gait. After the fourth exchange he noted a marked decrease in numbness and tingling. The tactile deficit rapidly receded so that four days after the last exchange sensation was impaired only over the distal $2 \mathrm{~cm}$ of the fingers and toes. Both knee jerks and the right triceps jerk returned. Postural sense improved rapidly and was judged as normal six days after the last exchange. Improvement was more rapid than on any of the occasions when steroids, ACTH or azathioprine had been used. He has remained well and, 36 months later, is symptom free.

Case 6 (RFH No BC 5665) A 47-year-old man had an 8 year history of refractory anaemia, lymphadenopathy, arthalgia, intermittent fever and hepatosplenomegaly. An episode of mesenteric venous thrombosis required bowel resection in 1977 . He had mild diabetes, controlled by diet, and beta thalassaemia trait. The blood picture and bone marrow findings were compatible with myelofibrosis, and a platelet count of $8000 / \mathrm{cmm}$ was associated with antiplatelet antibodies. Antinuclear factor was positive and DNA binding was constantly negative. Hepatitis B surface antigen was positive as was the DNA polymerase. He had received steroids in 1976 and cytotoxic drugs (including vincristine) in 1977. He underwent splenectomy in 1978. In February 1980 he developed a progressive, symmetrical distal, sensorimotor polyneuropathy. The weakness and sensory loss progressed over six weeks and he became areflexic. His condition remained stable for a month, and he then deteriorated further over a period of two weeks, until he was unable to get up from the sitting posture and needed a stick to walk. Examination of the CSF (in May 1980) showed a protein of $1.6 \mathrm{~g} / \mathrm{l}$ but no cells. His disability progressed still further over the next few weeks despite the use of prednisolone (60 mg/day), azathioprine $(100 \mathrm{mg} /$ day) and a three day course of cyclosporin $(20 \mathrm{mg} / \mathrm{kg} / \mathrm{day})$. Nerve conduction studies showed reduced motor conduction velocities. His neurological state had remained static for at least a week when his immunosuppressive therapy was stopped and he was given 4 litre plasma exchanges (with 3 litres plasma protein fraction and 1 litre fresh frozen plasma) on five occasions. After the fifth exchange there was slight improvement in power and position sense and walking without a stick again became possible. The improvement was only maintained for a few days. A further relapse occurred three weeks after the last exchange.

\section{Discussion}

Of these six patients with inflammatory polyneuropathy, four had acute and two had the chronic relapsing form of the disease. Three of the six cases were deteriorating neurologically at the time of the plasma exchanges. All of these cases improved rapidly. They were the three youngest patients in our series and they had the least muscle wasting. The three in whom response was slower already had marked wasting before plasma exchange was initiated. It is probable that cases 1, 2 and 4 would have required ventilation, but this was avoided in all three instances. Within seven days of the final exchange cases 1 and 4 had improved very substantially. Cases 2 and 6 improved only slightly (in case 6 this was sufficient, nevertheless, for the patient to walk unaided instead of needing a stick). Case 3 showed no signs of improvement one week after the last exchange. Case 6 relapsed after completion of a course of exchanges. His hepatitis B status prevented further management along these lines.

It is difficult to assess the effects of treatment in a disorder such as acute inflammatory polyneuropathy. Most cases recover spontaneously. However in our patients the rate of improvement following the exchanges suggested a therapeutic effect. Case 5 had had a number of earlier relapses treated with either prednisone, ACTH or azathioprine. Clinical improvement on these regimes had never started before two weeks and had never been 
complete before two months. With plasma exchange improvement was almost immediate, and has been sustained. Case 4 developed acute inflammatory polyneuritis whilst being successfully haemodialysed. The absence of $F$ waves confirmed the radicular nature of her neuropathy and made it unlikely that uraemia was responsible. Case 6 improved with plasma exchange whereas prednisone and azathioprine had had no effect. Other reported cases have also shown a rapid recovery. ${ }^{27} 303233$ Rail and others $^{34}$ reported improvement of nerve conduction with return of $F$ waves in a case of acute inflammatory polyneuropathy one hour after plasma exchange. We do not have nerve conduction data on the acute effects of plasma exchange. In general improvements in nerve conduction were less striking than the clinical progress.

Clinical recovery was in general too rapid to be explained by remyelination, and it appears more likely that some factor producing a readily reversible conduction block was being removed. This factor could still be antibody, for transient myelin damage with rapid recovery can be produced in vitro by anti-myelin antibody in the absence of complement. ${ }^{35}$ Other substances could also be responsible: plasma exchange with plasma protein fraction not only depletes immunoglobulin but also cell secretion factors, immune complexes, mediators of inflammation (including acute phase proteins for example, complement, fibrinogen) and antigen. There are also biochemical effects and probably effects due to temperature, although these are reduced by adding potassium and calcium to the replacement fluids and warming the water bath. Measurement of serum calcium and potassium levels before and after plasma exchange showed no significant change. Acute inflammatory polyneuropathy seems in most cases to be a "single shot" disease, and reversal of the acute process, spontaneously or by plasma exchange, usually leads to complete recovery without relapse. However in chronic relapsing cases the benefits of plasma exchange in an individual relapse may be transient, and immunosuppressive drugs may be needed as well. ${ }^{33}$ This may reflect a different pathogenesis, as suggested by their HLA association $^{36}$ which is not seen in the acute disease. ${ }^{37}$

Our cases and others reported in the literature suggest that plasma exchange has a place in the treatment of inflammatory polyneuropathy, and also suggests which patients are most likely to benefit. Patients with a chronic relapsing disease appear to respond well, and among acute cases the best results are probably obtained in young patients, in those whose disease is at an early stage and still progressing, and in those without severe muscle wasting. In addition we suggest that plasma exchange should be tried in any patient whose ventilation is failing, before mechanical assistance is necessary. These are of course preliminary criteria, and others will doubtless be found in the future. Clarification is needed not only concerning the most suitable patients but also concerning the technique and particularly the total volume of plasma to be exchanged. We have aimed for $55 \mathrm{ml} / \mathrm{kg}$ exchanges on four consecutive days, which is more than is usually employed. However, this volume may still not be sufficient to remove a tightly bound tissue factor, even though $60 \%$ of total IgG would be lost. ${ }^{38}$ Further studies of this aspect of treatment, as well as more extensive experience of its clinical use, will be needed before the role of plasma exchange in the management of acute inflammatory polyneuropathy can be fully assessed.

We thank Dr H Baron for referring case 4; and Dr J Moorhead and Professor B Hoffbrand for allowing one of us (MLPG) to treat their patients (cases 5 and 6). MLPG was in receipt of an Action Research Training Fellowship during part of this study.

\section{References}

' Arnason BGW. Inflammatory polyradiculoneuropathies. Chapter 6 Vol 2. Dyck PJ, Thomas PK, Lambert EH, eds. In: Peripheral Neuropathy. Philadelphia: WB Saunders Company, 1975:1110-48.

${ }^{2}$ Hughes RAC. Acute inflammatory polyneuropathy. In: Rose FC, ed. Clinical Neuroimmunology. Oxford: Blackwell Scientific Publ, 1979:170-84.

${ }^{3}$ Waksman BH, Adams RD. Allergic neuritis: an experimental disease of rabbits induced by the injection of peripheral nervous tissue and adjuvants. $J$ Exp Med 1955;102:213-35.

${ }^{4}$ Melnick SC. Thirty eight cases of the Guillain-Barré syndrome: An immunological study. $\mathrm{Br} \mathrm{Med} J$ 1963;1:368-73.

${ }^{5}$ Cook SD, Dowling PC, Murray MR, Whittaker JN. Circulating demyelinating factors in acute idiopathic polyneuropathy. Arch Neurol 1971;24:136-42.

- Yonezawa T, Ishihara Y, Matsuyama H. Studies on experimental allergic peripheral neuritis, II. Demyelinating patterns studied in vitro. $J$ Neuropathol Exp Neurol 1968;27:453.

' Luijten JAFM, Baart de la Faille-Kuyper EH. The occurrence of IgM and complement factors along myelin sheaths of peripheral nerves. An immunohistochemical study of Guillain-Barré syndrome. $J$ Neurol Sci 1972;15:219-24.

${ }^{8}$ Schott BH, Camer H, Chagot G, Brady B, Barbaret C. Immunofluorescence and immune labelling with $\mathrm{H}-\mathrm{R}$ peroxidase in the peripheral neuropathies. Excerpta Medica 1977;477:182.

${ }^{9}$ Nyland H, Aarli JA. Guillain-Barré syndrome: Demonstration of antibodies to peripheral nerve tissue. Acta Neurol Scand 1978;58:35-43. 
${ }^{10}$ Tse KS, Arbesman CE, Thomasi Jr TB, Tourville D. Demonstration of antimyelin antibodies by immunofluorescence in Guillain-Barré syndrome. Clin Exp Immunol 1971;8:881-7.

"Tacovsky T, Lisak RP, Koprowski H, Theofitopoulos AN, Dixon FJ. Circulating immune complexes in multiple sclerosis and other neurological disorders. Lancet 1976;2:997-9.

12 Goust JM, Chenais F, Canes JE, Hames CG, Fudenberg $\mathrm{HH}$, Hogan EL. Abnormal T cell populations and circulating immune complexes in the Guillain-Barré syndrome and multiple sclerosis. Neurology (Minneap) 1978;28:421-5.

${ }^{13}$ Faber, V, Balslov JT. Immunofluorescent studies of renal biopsies in acute polyradiculitis. Acta Path Microbiol Scand 1970;78:655-6.

${ }^{14}$ Saida T, Saida K, Silverberg DH, Brown MJ. Transfer of demyelination by intraneural injection of experimental allergic neuritis serum. Nature 1978;272:639-41.

${ }^{15}$ Hahn AF, Gilbert JJ, Feasby TE. Passive transfer of demyelination by experimental allergic neuritis serum. Acta Neuropathol (Berl) 1980;49:169-76.

${ }^{16}$ Hughes RAC, Newsom Davies JM, Perkin GD, Pierce JM. Controlled clinical trial of prednisolone in acute polyneuropathy. Lancet 1978;2:750-3.

${ }^{17}$ Hughes RAC, Kadlubowski M, Hufschmidt A. Treatment of acute inflammatory polyneuropathy. Ann Neurol 1981 (in press).

18 Dowling PC, Bosch VV, Cook SD. Possible beneficial effect of high dose intravenous steroid therapy in acute demyelinating disease and transverse myelitis. Neurology (Minneap) 1980;30:33-36.

19 Yuill GM, Swinburn WR, Liversedge LA. Treatment of polyneuropathy with azathioprine. Lancet 1970;2:854.

${ }^{20}$ Rosen AD, Vastola EF. Clinical effects of cyclophosphamide in Guillain-Barré polyneuritis. J Neuro Sci 1976;30:179-87.

${ }^{21}$ Palmer KNV. Polyradiculoneuropathy (GBS) treated with 6-mercaptopurine. Lancet 1965;1:733-4.

${ }^{22}$ Drachman DA, Paterson PY, Berlin BS, Rogusta J. Immunosuppression and the Guillain-Barré syndrome. Arch Neurol 1970;23:385-93.

${ }^{23}$ Julien J, Vital CL, Aupy G, Lagueny A, Darriet A, Brechenmacher C. GBS and Hodgkin's disease. J Neurol Sci 1980;45:23-27.

${ }^{24}$ Brettle RP, Gross M, Legg NJ, Lockwood M, Pallis C. Treatment of acute polyneuropathy by plasma exchange. (Letter) Lancet 1978;2:1100.

${ }^{25}$ Server AC, Lefkowitch J, Braine H, McKhann GM. Treatment of chronic relapsing inflammatory polyradiculoneuropathy by plasma exchange. Ann Neurol 1979;6:258-61.
${ }^{26}$ Server AC, Stein SA, Braine H, Tandon DS, McKhann GM. Experience with plasma exchange and cyclophosphamide in the treatment of chronic relapsing inflammatory polyradiculoneuropathy. (Abstract) Neurology (Minneap) 1980;30:362.

${ }^{27}$ Cook SD, Tindall RAS, Walker J, Khan A, Rosenberg R. Plasma exchange as a treatment of acute and chronic idiopathic autoimmune polyneuropathy: limited success. (Abstract) Neurology (Minneap) 1980;30:361.

${ }^{28}$ Mark B, Hurwitz BJ, Olanow CW, Fay JW. Plasmapheresis in idiopathic inflammatory polyneuropathy (Abstract). Neurology (Minneap) $1980 ; 30: 361$.

${ }^{29}$ Ropper AH, Shahani B, Huggins CE. Improvement in four patients with acute Guillain-Barré syndrome after plasma exchange (Abstract). Neurology (Minneap) 1980;30:361.

${ }^{30}$ Rumpl E, Mayr U, Gerstenbrand F, Hackl JM, Rosmanith P, Aichner F. Treatment of Guillain-Barré syndrome by plasma exchange. $J$ Neurol 1981;225:207-17.

${ }^{31}$ Gross MLP, Baillod R, Sweny P, Pearson RM. Plasma exchange and haemodialysis as a combined procedure. Plasma Therapy 1981;2,4:255.

${ }^{32}$ Levy RL, Newkirk R, Ochoa J. Treatment of chronic relapsing Guillain-Barré syndrome by plasma exchange. Lancet 1969;2:741.

${ }^{33}$ Gross MLP, Thomas PK. The treatment of chronic progressive and chronic relapsing polyneuropathy by plasma exchange. J Neurol Sci 1981;52:69-78.

${ }^{34}$ Rail D, Stark R, Swash M, Newland A. Improvement in nerve conduction after plasma exchange for Guillain-Barré syndrome. J Neurol Neursurg Psychiatry 1980;43:1147.

${ }^{35}$ Raine CS, Bornstein MB. Experimental allergic neuritis: ultrastructure of serum-induced myelin aberrations in peripheral nervous system cultures. Lab Invest 1979;40:423-32.

${ }^{36}$ Adams D, Festenstein H, Gibson JD, Hughes RAC, Jaraquemada J, Papasteriadis C, Sachs J, Thomas PK. HLA antigens in chronic relapsing idiopathic inflammatory polyneuropathy. J Neurol Neurosurg Psychiatry 1979;42:184-6.

${ }^{37}$ Adams D, Gibson JD, Thomas PK, Batchelor JR, Hughes RAC, Kennedy L, Festenstein H, Sachs J. HLA antigens in Guillain-Barré syndrome. Lancet 1977;2:504-5.

${ }^{38}$ Lockwood MC, Rees AJ, Pearson TA, Evans DJ, Peters DK, Wilson CB. Immunosuppression and plasma exchange in the treatment of Goodpasture's syndrome. Lancet 1976;1:711-5. 